\title{
Bioethical and Biosafety Issues in Biomaterials Used in Oral Rehabilitation
}

\author{
D'Souza DSJ* and Atanu Bhanja \\ Department of Dental Surgery, Sikkim Manipal Institute of Medical Sciences, India
}

Submission: March 23, 2017; Published: April 12, 2017

*Corresponding author: D’Souza DSJ, Department of Dental Surgery, Sikkim Manipal Institute of Medical Sciences, India; Email: dsjdsouza@gmail.com

\begin{abstract}
With recent advances in biotechnology, there has been a plethora of biomaterials in the form of various dental materials and maxillofacial implants, being routinely used for comprehensive oral rehabilitation. Even though these have considerably enhanced the treatment outcomes, but at times the improper application and lack of safety precaution with these have raised many moral and ethical issues. Due to commercial and marketing pressures, technological developments in biomaterials have led to ethical issues being conveniently buried. Lack of stringent regulations and want of strict institutional control results in products that are not truly safe for patients to be marketed and used by unsuspecting clinicians.
\end{abstract}

Clinicians need to be aware of the various bio-safety aspects of the biomaterials that are commonly in use and also ensure that the patients' rights of informed consent, beneficence, non-malfeasance and autonomy are protected. There is an urgent need for all healthcare specialists to be aware of the bioethical concerns associated with these advanced materials and technologies so that they are better equipped to utilise them safely and confidently.

\section{Introduction}

The field of biotechnology today is moving ahead at a rapid pace with newer products and superior biomaterials for oral rehabilitation being constantly discovered, however the mandatory level of simultaneous clinical applications research always seems to be playing catch-up. There are inherent safety related checks and balances within the system when it comes to clinical trials and bio-safety issues in animals and human trials, yet this time lag is often considered as an unnecessary hurdle or speed bump on the road to progress. It is crucial that the clinical trials follow all the steps and systematic reviews that are necessary to ensure that all manufacturer claims are verified and adverse reactions are minimal if not nil. Clinicians also need to be aware of the potential danger in using biomaterials that are not properly tested and should not be swayed by promotional pressure from marketing agents.

\section{Biomaterials and oral rehabilitation}

The use of a wide array of biomaterials for oral rehabilitation has been known from the earliest times. Extracted teeth, silver, gold and a mind-boggling range of other materials are recorded as having being utilised with varying degrees of success in the maxillofacial region [1]. While the uses of biomaterials in other applications in the human body have been fairly predictable and successful there are myriad challenges in the rehabilitation of the oral and maxillofacial region. The presence of saliva, interaction with food and other commonly consumed liquid sand the physical assault of Masticatory forces all causes significant stress and wear and tear on the biomaterials used in the oral cavity.

In recent years, there has been a plethora of biomaterials and related biomedical technology, in the form of various rehabilitative dental materials and maxillofacial implants, being routinely used for comprehensive oral rehabilitation. Undoubtedly these have all dramatically improved the scope of treatment, but, these advancements have raised many moral and ethical issues. As the goal to be the first in the market is paramount, many a time, commercially-driven technological development in biomaterials have led to ethical issues being conveniently buried. Laxity in regulations and want of strict institutional control results in products that are not truly safe for the patients to be marketed freely and may also further lead to products that are not fully licensed to enter into the system.

Responsible clinicians need to be aware of the various biosafety aspects of the biomaterials that are commonly in use and also ensure that the patients' rights of beneficence, nonmaleficence and autonomy are protected. There is an urgent need for all healthcare specialists to be aware of the bioethical 
concerns associated with these advanced materials and technologies so that they are better equipped to utilise them safely and confidently.

\section{Biocompatibility and biosafety}

Biocompatibility maybe described as the property of a biomaterial to function in a predictable manner when applied to the body, without causing a chronic inflammatory reaction, undesirable biological response, foreign body reaction or toxicity, as a result of interaction between the host tissues and the biomaterial [2]. There is no single material that is completely inert from the physiological point of view since, one or more of the components may be potentially toxic or irritating3. In addition, chemical by-products produced during cure of the material or as a result of interaction with other materials in the region may also produce undesirable effects [3]. It is therefore imperative that all clinicians have an in-depth knowledge about the characteristics and properties of materials and their likely interaction within the biological environment before utilizing them for oral rehabilitation.

There is a wide range of adverse biological events following the utilization of restorative materials in the oral region and therefore biocompatibility testing has to be undertaken as a strategic and structured approach. Present consensus on testing of biocompatibility is that the method should be rapid and costeffective and also by avoiding animal testing as far as practicable. Modern test designs try to simulate the in-vivo situation as closely as possible. This may be accomplished by including suitable barriers between the material and the target cells, by constructing appropriate target cells, and or by applying biomarkers for estimating the biological side effects [4].

Commonly adverse reactions to materials used for oral rehabilitation occur as a result of their direct contact with soft or mineralized tissues, or due to leaching out of some corrosion or degradation by-products. The use ofmultiple metallic restorations manufactured from alloys with differing compositions will show a more rapid degradation when immersed in saliva due to galvanic action. If these chemical by-products are ingested, they may manifest as both local or systemic reactions [5]. Materials designed for oral use are manufactured with the aim of being inert and insoluble. The quanta of leachable components are minimal and so routinely toxic reactions are unlikely to occur. Despite this fact, severe allergic reaction may be provoked in a sensitized individual by even miniscule concentrations of the allergen [6]. Thus contact allergic reactions (Type IV reactions) are the most common observed as side effects in the dental clinic. Assessment of possible reactions to the biomaterials is therefore a constant challenge and all clinicians must be aware of and report any adverse outcomes promptly and thoroughly [7-9].

When evaluating adverse reactions to materials used in prosthodontic appliances, a variety of situations must therefore be taken into consideration. This is because some materials come only in brief contact with the patients such as when making an impression or registering a bite of the patient. In contrast, dental prostheses are intended to remain in-situ for decades. A number of factors need to be taken into account when estimating adverse biological reactions to prosthodontic materials [5]. Among these include: the type, form, contour, extent of the prosthesis, any medication used by the patient, salivary flow rate, xerostomia, oral hygiene, quality of fit, and function of the prosthesis. All these conditions may affect local reactions in addition to those caused by the materials per se [10]. Biological films, 'pellicles', of salivary origin will also accumulate on the materials. They differ in composition depending on the material and on the properties of the patients' saliva. The irrigating effect of saliva is also difficult to assess. However, a distinct difference exists between material reactions intra-orally and extra-orally, with those on skin being more frequent and more severe [11].

\section{Bio-safety concerns of biomaterials}

Casting alloys: The alloys commonly used for manufacturing of dental prostheses contain varying amounts of trace metals such as nickel, chromium, cobalt, cadmium and beryllium. These are known to cause potentially hazardous reactions and are of concern especially for the dental technicians during the casting and finishing procedures. Adverse reactions in the oral cavity to casting alloys are observed due to release of components from the alloys, following corrosion when immersed in saliva [12-15].

Polymer-based restorative materials: Many of the restorative materials used in oral rehabilitation are polymerized resin-based materials that are cured by heat, light, or by chemical activators at room or mouth temperature. Their composition includes accelerators (amines), co-polymers, such as butyl-methacrylate (BMA), plasticizing agents such as dibutyl-phthalate, and inhibitors such as hydroquinone. Various shade matching components to simulate natural tooth and gingiva colour are also present. These may not pose a danger for clinical use in patients' but have a potential hazard to the dental mechanics who routinely grind and polish the prosthesis made from these resin-based materials. If the materials are not fully cured in the dental laboratory, the presence of free monomer radicals of methyl methacrylate may cause toxic reactions or allergic responses in previously sensitized individuals [16-19].

Implant materials: The field of oral rehabilitation was dramatically transformed by the demonstration of 'osseo integration' of alveolar bone with titanium implants, as described by Brane mark. Since then many materials have been used to manufacture dental implants, such as high impact polymers, cobalt-chromium alloys, vitreous carbon, titanium, and aluminium oxide alloys, ceramic, and synthetic hydroxylapatite [20]. The main research has been focussed on the region or interfaces between alveolar bone and the implant as well as ultramicroscopic studies on the pattern of in-growth of bone into the implant surface. One of the main reasons for the failure of dental implants is due to failure of osseointegration. 
This may be primary failure due to improper surgical technique; or it may be secondary following loading of the implant, and secondary infection [20]. Another area that needs investigation is the effect of nano-particles of metals, polyethylene, and ceramics which cause a biological response at the implant bone interface. Focussed research is vital for comprehensive biosafety evaluations of implant biomaterials and biological effects of nano-toxicology both from the aspect of biomedical applications and the long term in-vivo effects [21,22].

Graft materials: There are many types of bone graft materials being routinely used for oral rehabilitation. These may be auto grafts, xenografts or allografts. The known sources for xenografts are bovine bone, porcine bone, horse bone and natural coral. Despite the claims of absolute safety of these products, the discovery of bovine spongiform encephalopathy (BSE) and porcine endogenous retroviruses (PERVs) needs to be kept in mind [23]. Ethically as well, the need to inform the patients of the source of the graft materials is mandatory where the patient may have some religious reservations against certain types of grafts. The method of sourcing and bio-safety testing must be definitely checked by the clinician before opting to use any of these graft materials

\section{Conclusion}

There is an increased demand on the various materials being utilized for oral rehabilitation to be functionally biocompatible, esthetically acceptable and economically viable for all groups of patients. It is therefore imperative that better strategies are designed to evaluate, predict, and assess material safety aspects both at the manufacturing hub as well as the consumer end. The researchers must be ethical in their reporting of in-vitro and in-vivo effects of all novel bio-materials as well as newer technologies to treat oral disease. Clinically driven research networks and practitioner groups should be involved in ethically driven patient trials to ensure that all newer products or technology goes through exhaustive and systematic clinical evaluation. Reliable research protocols will ensure that the various bio-safety aspects are looked after and the frequency of adverse reactions in oral rehabilitation is minimized. There is an ethical and moral requirement for all clinicians to be aware of the limitations, outcomes, reactions of the various materials that they routinely employ in the oral rehabilitation of the patients. Evidence-based evaluation must be the watchword and clinicians must be careful not to be swayed by commercial and marketing pressures.

\section{References}

1. Van Noort R, Barbour ME (2013) Introduction to Dental Materials 4: Introduction to Dental Materials. Elsevier Health Sciences.

2. Freire WP, Fook MV, Barbosa EF, dos S Araújo C, Barbosa RC, et al (2014) Biocompatibility of Dental Restorative Materials. In Materials Science Forum 805: 19-25.
3. Schmalz G (1998) Concepts in biocompatibility testing of dental restorative materials. Clin Oral Investig 1(4): 154-162.

4. John KR (2007) Biocompatibility of dental materials. Dental Clinics of North America 51(3): 747-760.

5. Wataha JC (2012) Predicting clinical biological responses to dental materials. Dental Materials 28(1): 23-40.

6. Hensten-Pettersen A (1998) Skin and mucosal reactions associated with dental materials. European Journal of Oral Sciences 106(2pt2): 707-712.

7. Lygre H (2002) Prosthodontic biomaterials and adverse reactions: a critical review of the clinical and research literature. Acta Odontol Scand 60(1): 1-9.

8. Mjör IA (1992) Problems and benefits associated with restorative materials: Side-effects and long-term cost. Adv Dent Res 6: 7-16.

9. Van Noort R, Gjerdet NR, Schedle A, Björkman L, Berglund A (2004) The current status of national reporting systems for adverse reactions to dental materials. J Dent 32(5): 351-358.

10. Tillberg A, Järvholm B, Berglund A (2008) Risks with dental materials. Dent Mater 24(7): 940-943.

11. Cobos-Fuentes MJ, Martinez-Sahuquillo-Marquez A, Gallardo-Castillo I, Armas- Padron JR, Moreno-Fernandez A, et al. (2009) Oral lichenoid lesions related to contact with dental materials: A literature review. Med Oral Patol Oral Cir Bucal14(10): e514-520.

12. Moffa JF, Beck W, Hake A (1977) Allergic response to nickel-containing alloys. J Dent Res 56: B78.

13. Mjör IA, Christensen GJ (1993) Assessment of local side effects of casting alloys. Quintessence Int 24(5): 343-351.

14. De Melo JF, Gjerdet NR, Erichsen ES (1983) Metal release from cobaltchromium partial dentures in the mouth. Acta Odontol Scand 41(2): 71-74.

15. Kallus T, Mjor IA (1991) Incidence of adverse effects of dental materials. Scand J Dent Res 99(3): 236-240.

16. Schweikl H, Hiller KA, Bolay C, Kreissl M, Kreismann W, et al. (2005) Cytotoxic and mutagenic effects of dental composite materials. Biomaterials 26: 1713-1719.

17. Becher R, Kopperud HM, Al RH, Samuelsen JT, Morisbak E, et al. (2006) Pattern of cell death after in vitro exposure to GDMA, TEGDMA, HEMA and two compomer extracts. Dent Mater 22(7): 630-640.

18. Goldberg M (2008) In vitro and in vivo studies on the toxicity of dental resin components: A review. Clin Oral Investig 12(1): 1-8.

19. Ansteinsson VE, Samuelsen JT, Dahl JE (2009) Filler particles used in dental biomaterials induce production and release of inflammatory mediators in vitro. J Biomed Mater Res B Appl Biomater 89(1): 86-92.

20. Lemons JE (1990) Dental implant biomaterials. The Journal of the American Dental Association. 121(6): 716-719.

21. Mendonça G, Mendonça DB, Aragao FJ, Cooper LF (2008) Advancing dental implant surface technology-from micron-to nanotopography. Biomaterials 29(28): 3822-3835.

22. Zhang YF (2011) The potential biohazards of nanosized wear particles at bone- prosthesis interface: Asia-Pac. J Chem Eng 6: 563-568.

23. Nasr HF, Aichelmann-Reidy ME, Yukna RA (1991) Bone and bone substitutes. Periodontology 2000 (19): 74-86. 


\section{Your next submission with Juniper Publishers} will reach you the below assets

- Quality Editorial service

- Swift Peer Review

- Reprints availability

- E-prints Service

- Manuscript Podcast for convenient understanding

- Global attainment for your research

- Manuscript accessibility in different formats ( Pdf, E-pub, Full Text, Audio)

- Unceasing customer service

Track the below URL for one-step submission https://juniperpublishers.com/online-submission.php 